\title{
A Study on the Development of Various Domestic Transportation Modes
}

\author{
Jianhua Zhang ${ }^{1}$, Yamin Zhao ${ }^{1, *}$, and Xiaomin Guo ${ }^{1}$ \\ ${ }^{1}$ Management Engineering Department, Zhengzhou University, Zhengzhou, China
}

Keywords: Mode of transport; Status; Problems; Strategy

\begin{abstract}
The transportation is very important for national economy and people's livelihood, which is the foundation to realize the sustainable development of economy in China. With the rapid development of China's national economy, transportation industry has gained a certain progress and development. To make development and research on various mode of transportation in China, promote the orderly conduct of the transportation, this paper, reviews the current situation of domestic mode of transport, and through the analysis of current problems of transportation in the whole, puts forward the countermeasures to promote its development.
\end{abstract}

\section{INTRODUCTION}

Economic globalization today, the transport industry as an important part of China's national economic development, has been carrying an important function. In today's fast-growing economy, transportation is essential, it not only facilitates people's travel, but also for the development of the national economy transport a large number of materials and human resources. In order to effectively promote the sustainable development of the national economy, the development of the transportation industry should keep pace with the times. However, with the increase of mileage, the increase of carrying capacity, the rapid development of infrastructure, the transportation pressure and management difficulty in transportation gradually increase, and the transportation industry faces severe challenges. Transportation on the one hand to break the traditional management system, accelerate the pace of reform. On the other hand continue to optimize the service, improve quality and efficiency. So as to create more economic and social benefits for the community.

\section{THE DEVELOPMENT OF VAR-IOUS DOMESTIC MODES OF TRANSPORT}

The transportation mode is divided into five modes: railway transportation, road transportation, water transportation, air transportation and pipeline transportation. The present situation of these five modes of transportation is described separately.

\subsection{Development Status of Domestic Railway Transportation}

(1) Infrastructure. According to the data provided by the National Railway Administration's "Railway Statistics Bulletin 2015", the national railway mileage will reach $121,000 \mathrm{~km}$ by 2015 , up $8.2 \%$ from the previous year. Various types of mileage development as shown in Figure 1.

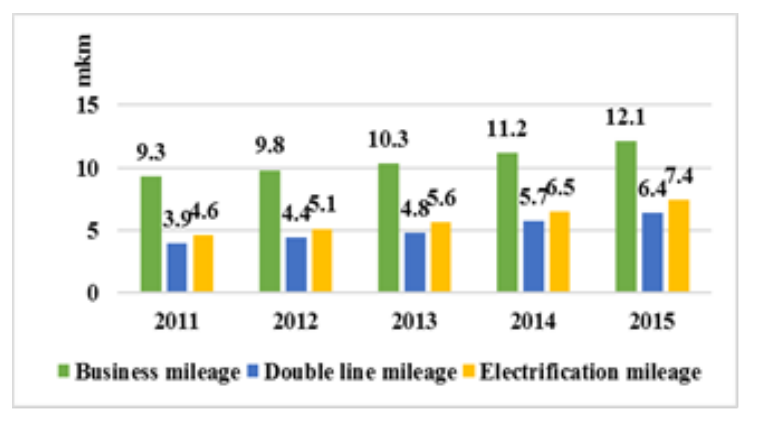

Figure 1 2011-2015 National railway operating mileage.

(2) Passenger transport. National railway passenger shipments completed 2.535 billion people, an increase of 230 million people over the previous year, an increase of $10.0 \%$. National railway passenger turnover completed 11960.6 billion personkilometer,

An increase of 71.876 billion personkilometers, an increase of $6.4 \%$. The specific composition of passenger traffic is shown in Table 1 . Nearly five years, the national railway passenger volume is also in an increasing trend, as shown in Figure 2.

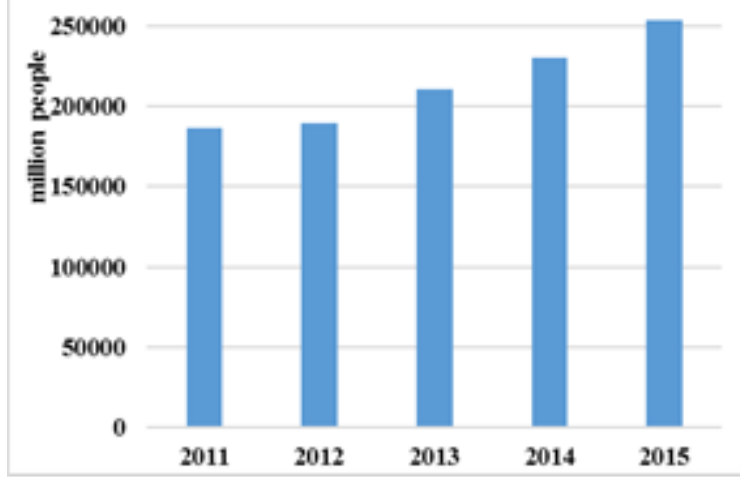

Figure 2 2011-2015 National Railway passenger shipmets.

(3) Cargo transportation. The total delivery volume of the national rail freight was 3.358 billion tons, down by 45.5 million tons or $11.9 \%$ over the previous year. The total turnover of rail transport in the country was 237.554 billion tons, down by 377.588 billion tons or $13.7 \%$ over the previous year. The total volume of railway freight in recent years as shown in Figure 3. 


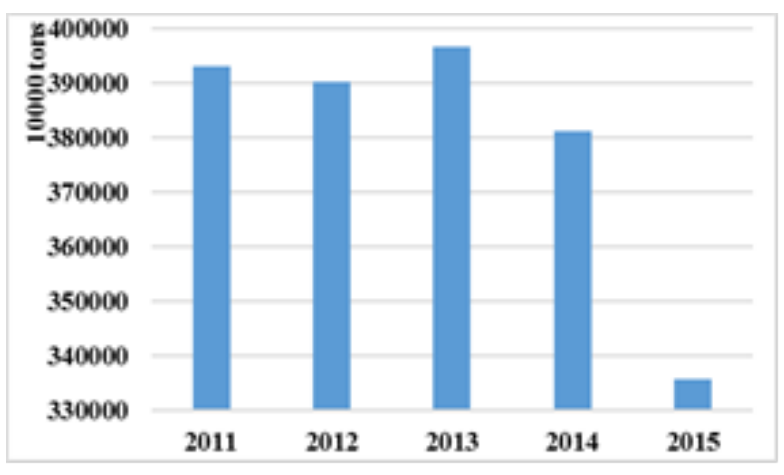

Figure 3 2011-2015Total Railway Freight Transport Volume.

\subsection{Development Status of Domestic Highway Transportation}

(1) Infrastructure. By the end of 2015 the total mileage of the national highway 457.73 million kilometers, an increase of 113,400 kilometers over the previous year. Highway density of $47.68 \mathrm{~km} \mathrm{/} 100$ square kilometers, an increase of $1.18 \mathrm{~km} / 100$ square kilometers. Highway maintenance mileage of 446.56 million kilometers, accounting for $97.6 \%$ of the total mileage of the road. As shown in Figure 4.

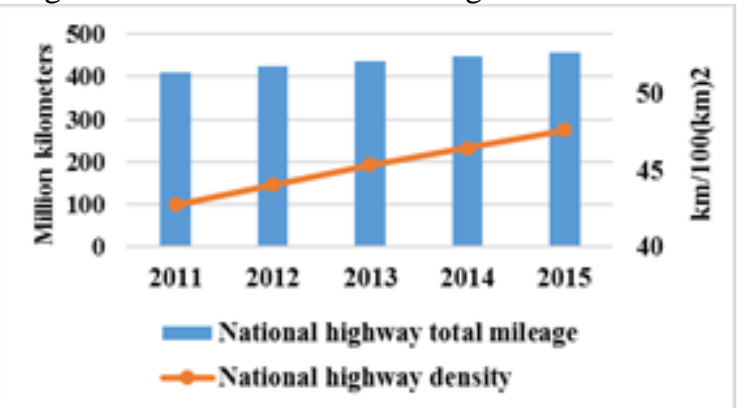

Figure 4 2011-2015Total highway mileage and highway density.

National highway bridge 779,200, 45.9277 million meters, an increase of 22,000 over the previous year, 3.348 million meters. Among them, 3894 large bridge, 690.42 million meters, 79512 bridges, 2060.85 million meters. The national highway tunnel is 14006, 12.6839 million meters, an increase of 1602, 192.72 million meters. Among them, the long tunnel 744, 329.98 million meters, 3134 long tunnel, 537.68 million meters.

(2)Passenger transport. Throughout the year, the number of passenger trades was 16.191 billion, and the passenger turnover was 107.4266 billion personkilometers, down by $6.7 \%$ and $2.3 \%$ respectively over the previous year. The average distance was 66.35 kilometers.

(3)Cargo transportation. National cargo freight vehicles completed 31,100 million tons of cargo, cargo turnover of 5795.572 billion tons $\mathrm{km}$, respectively, over the previous year increased by $1.2 \%$ and $2.0 \%$, the average distance of $183.99 \mathrm{~km}$. Passenger transport. Throughout the year, the number of passenger trades was 16.191 billion, and the passenger turnover was 107.4266 billion personkilometers, down by $6.7 \%$ and $2.3 \%$ respectively over the previous year. The average distance was 66.35 kilometers.

\subsection{Development Status of Domestic Water Transportation}

(1) Infrastructure.

1) Inland waterway. At the end of 2015 the national inland waterway navigation mileage of 12.70 million kilometers, an increase of 721 kilometers over the previous year. Grade channel 66,300 km, accounting for $52.2 \%$ of the total mileage, an increase of 0.4 percentage points. The mileage of the inland waterway is 1341 kilometers, the secondary channel is 3443 kilometers, the third channel is 6760 kilometers, the four waterway is 10,682 kilometers, the five waterway is 7862 kilometers, the six waterway is 18277 kilometers, the seven waterway is 17891 kilometers The And other external channels 60,700 km. As shown in Figure 5.

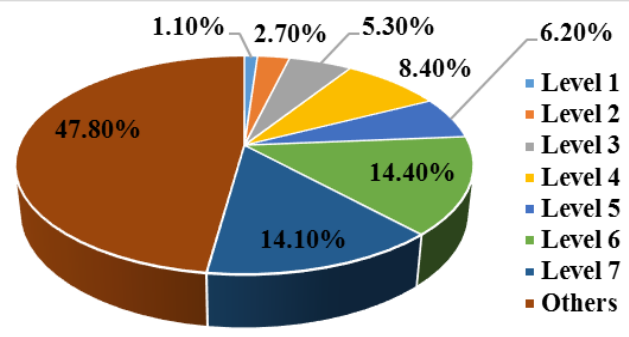

Figure 52015 inland riverway mileage composition.

The navigable river course of the river is 64852 kilometers, the Pearl River system is 16,450 kilometers, the Yellow River is 3488 kilometers, the Heilongjiang water is 8211 kilometers, the Beijing-Hangzhou canal is 1438 kilometers, the Minjiang River is 1973 kilometers and the Huaihe River is 17507 kilometers.

2) Port. At the end of 2015 the country's ports have 31259 berths for production, down 446 from the previous year. Among them, the coastal port production berths 5899, an increase of 65; inland port production terminal berth 25360, a decrease of 511. National ports have 20,000 tons and above berths 2221, an increase of 111 over the previous year. Among them, the coastal port of 10,000 tons and above berths 1807, an increase of 103; inland port million tons and above berth 414, an increase of eight.

Among the 100 tonnage and above berths, there are 1173 specialized berths, 473 general bulk berths, and 371 general cargo berths, an increase of 59, 32 and 11 respectively over the previous year. Section, subsection and sub subsection first paragraph should not have the first line indent, other paragraphs should have a first line indent of 0,5-centimeter.

(2) Passenger transport. In 2015, the country completed 271 million waterway passenger traffic, passenger turnover of 7.308 billion person-kilometers, an increase of $3.0 \%$ over the previous year and $1.7 \%$ reduction, the average distance of $27.00 \mathrm{~km}$. Througout the year between the two sides of the sea transport passenger traffic volume of 1.884 million, an increase of $9.0 \%$ over the previous year. National port passenger throughput of 185 million, an increase of $1.3 \%$ over the previous year. Among them, the coastal port to complete 82 million people, the river port completed 104 million people, each growing by $1.3 \%$.

(3) Cargo transportation. In 2015, the national 
waterway freight volume of 6.136 billion tons, cargo turnover of 91772.45 billion tons $\mathrm{km}$, up $2.6 \%$ over the previous year and a decrease of $1.1 \%$, the average distance of $1495.72 \mathrm{~km}$. In the national waterway freight, the river transport cargo volume of 3.459 billion tons, cargo turnover of 13312.41 billion tons $\mathrm{km}$; coastal transport cargo volume of 1.93 billion tons, cargo turnover of 242.243 billion tons $\mathrm{km}$; ocean freight completed 747 million tons of cargo, cargo turnover 54236.09 million tons $\mathrm{km}$. In recent years, port cargo throughput changes as shown in Figure 6.

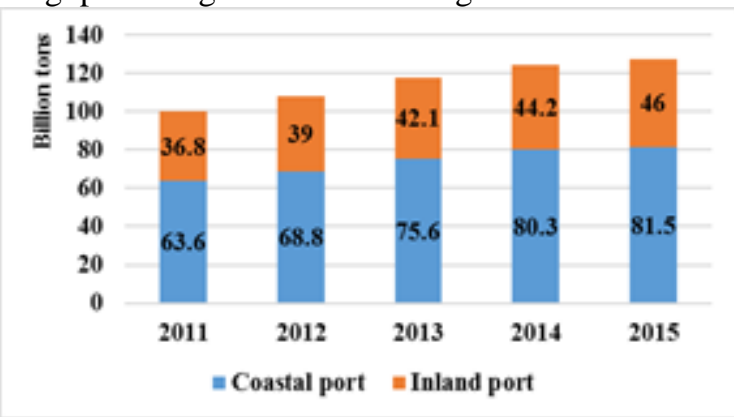

Figure 6215 Inland riverway mileage composition.

The linespace must be of exactly 11-point with 9point of font size and the font style set to italic.

\subsection{Development Status of Domestic Air Transportation}

(1) Infrastructure. At the end of 2015, there were 210 certified civil aviation airports, an increase of 8 over the previous year, of which there were 206 regular navigable airports and 204 regular flights. In 2013, there were 70 airports with a passenger throughput of more than 1 million passengers, an increase of 6 over the previous year, 26 of the annual passenger throughput of more than 10 million, an increase of 2 over the previous year. The annual cargo throughput of more than 10,000 tons of 51, an increase over the previous year (Xianglin Li, 2015).

(2) Passenger transport. Preliminary statistics, in 2015 the national civil aviation passenger transport volume of 436 million passengers, passenger turnover of 727.066 billion person-kilometers, an increase of $11.1 \%$ and $14.8 \%$ over the previous year. Civil Aviation Transport Airport completed passenger throughput of 915 million passengers, an increase of $10.0 \%$ over the previous year.

(3) Cargo transportation. Preliminary statistics, in 2015, the national civil aviation cargo traffic volume of 6.253 million tons, cargo and mail turnover of 20.727 billion tons $\mathrm{km}$, an increase of $5.3 \%$ and $10.4 \%$ over the previous year. Completion of cargo and mail throughput of 14.094 million tons, up 3.9\% over the previous year.

\subsection{Current Status of Domestic Pipeline Transportation}

(1) Infrastructure. Data from the National Bureau of Statistics show that in 2014 the national pipeline transport mileage reached 10.57 million $\mathrm{km}$, compared to 189 million in 2013 increased by $7.31 \%$. In 2014, fixed assets investment (excluding farmers) in the pipeline transportation industry reached RMB15547 million, a decrease of $15.65 \%$ compared with RMB37.4 billion in 2013. The specific situation shown in Figure 7 and Figure 8.

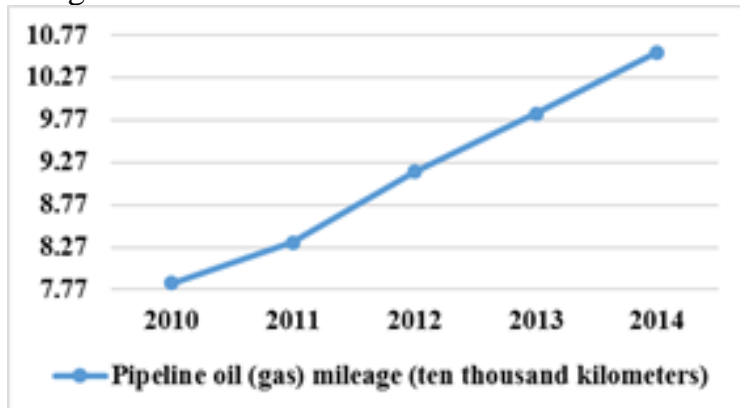

Figure 7 2010-2014 National pipeline oil (gas) mileage.

(2) Cargo transportation. In 2014, the national pipeline freight volume reached 737.52 million tons, compared to 2013, 65209 million tons increased by $13.10 \%$. The average transport distance of the pipeline cargo transport reached 586.87 kilometers, compared with 536.11 kilometers in 2013 increased by $9.47 \%$. The specific situation as shown in Figure 9.

\section{THE PROBLEMS IN THE WH- OLE TRANSPORTION}

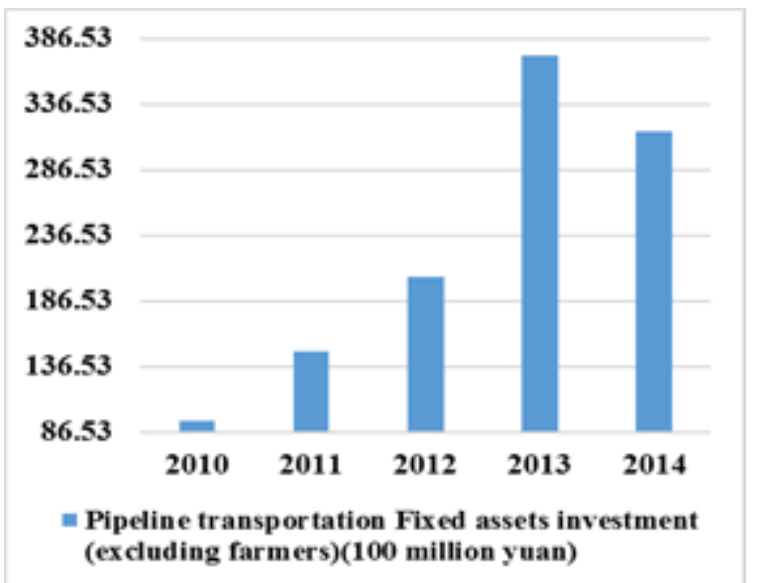

Figure 8 2010-2014 National fixed investment in pipeline transportation (excluding farmers).

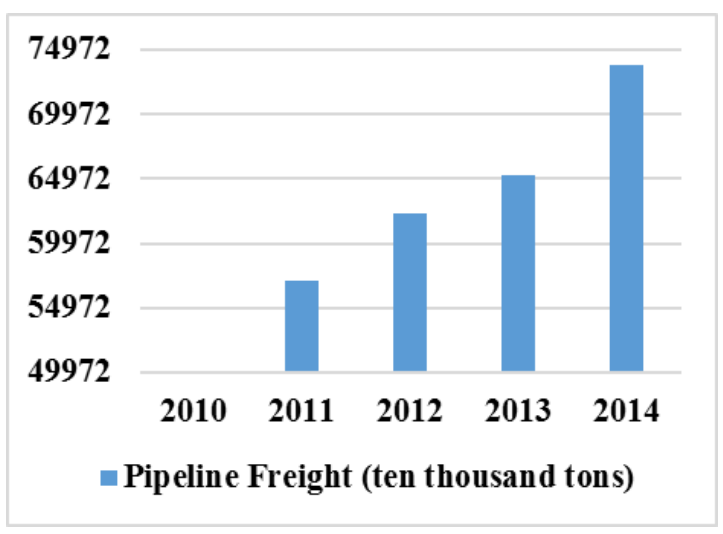

Figure 9 2010-2014 National Pipeline Freight Volume.

With the improvement of people's living standards and economic strength, China's traffic volume is also growing. At the same time, the transport structure is also improving. The proportion of rail transport is gradually 
reduced, the transport capacity of other modes of transport in the rapid increase (Liu Jia,201 6). Road, water and civil aviation potential to play at the same time, but also to a certain extent, reduce the pressure on rail transport. In general, a considerable number of areas of transport facilities are relatively backward, the Government still need to increase investment in infrastructure construction, technical and equipment level compared with the international advanced level is still a large gap between the overall transport capacity of large transport capacity, The overall efficiency of transport systems and service quality is not high, the overall reform lag, transportation can not fully meet the needs of rapid economic and social development. Mainly in the following areas.

(1)The overall transport capacity of the transport channel is insufficient. The lack of the necessary infrastructure to lose the channel, the flexibility of demand changes is small, the transport demand is very strong, but the service level is low, obviously can not meet the market demand. In recent years, oil, container, cement, coal, grain, steel, "three rural" materials and other cargo demand increased significantly, so that the original tight transport transport pressure increased. Especially as a transregional material transfer of the main railway, the contradiction is very prominent. Therefore, the port will be a large number of materials set, sparse, transport impact, so that the port also appears contradiction between supply and demand.

(2) The overall lack of integrated transport netw- ork. Now, China's crossregional transport problems are: high transport costs, lack of transport capacity, network density is not enough, low quality of transport services, infrastructure accessibility, the overall quality level is low, convenience, smoothness can not be better to meet The need for cargo transport. China's land area is comparable to that of the United States, while the railway mileage is only $33.3 \%$ of the total. The total mileage of the highway and the highway mileage are only $28.1 \%$ of the US, and the number of airports is only $2.6 \%$ of the US (Huibin Gong, 2015). Although the number of infrastructure to compare, and can not directly explain the real demand gap, but a variety of modes of transport are obvious at the same time, to a certain extent, reflects the backwardness of China's traffic.

(3)The convergence of the transport mode with poor ability. In the past, we only focus on the construction of theirown transport, while ignoring the comprehensive transport hub planning and construction. Integrated transport hub problems are: unreasonable facilities, transport of goods is not smooth, transport and urban transport can not be an effective combination. Sometimes even appear to expand the size of the hub, but it has aggravated the problem of traffic congestion. This not only restricts the efficiency of the integrated transport system, but also leads to a waste of resources. The convergence of the transport mode, has become an urgent need to solve the development of transport problems.

(4)The development of the transportation market is very uneven.

The problem is mainly manifested in two aspects:

(1) The unbalanced development of the transport market, that is, the rapid development of the waterway, road transport market, followed by the air transport market, and the slow progress in the railway and pipeline transportation markets.

(2) in the economically developed areas, because the construction of the transport market started earlier, strong demand, market mechanism to teach mature, so the construction of its transport market is also among the forefront. While in economically backward areas, the opposite is true.

\section{THE DEVELOPMENT STRATE- GY OF TRANSPORTATION}

In the scientific management, advanced technologydriven, the transport industry through the amount of accumulation, to achieve a qualitative leap. Including the United States, Japan, the more developed countries, including transport, are looking for new development strategies. Fine logistics, intelligent logistic-s, closedloop logistics, China's transportation industry had a greater impact. With the growth of the global economy, China's transportation industry will face more opportunities for development. According to the development of the global transportation industry, we can summarize the development trend of transportation in the 21st century: informationzation, networking, flexibility, standardization, socialization, etc. (Yilin An, 2016).

\subsection{Continue to Increase Investment in Infrastructure Construction}

China's transport infrastructure is relatively backward. The transportation industry is related to the national social production and life, is to promote the national economic development of the basic protection and prerequisites. At present, the industrialization process is in the stage of rapid development, the transportation industry in the national economy in the status and role of more prominent. Infrastructure construction as an important part of the development of the transport industry, the degree of improvement will directly affect the development of other industries, investment environment and the efficiency of the transaction. As a result, in recent years, the infrastructure of the expressway, trunk railway, international shipping center and hub airport has been vigorously developed.

\subsection{Further Improve the Transport and Logistics Information Network}

The structural adjustment of the transportation industry needs to be adjusted from six aspects: enterprise structure, management structure, capacity structure, transportation station layout, transportation origanization structure and personnel structure. Should completely break the ownership, regional, industry, departmental restrictions, the establishment of part of the transport enterprises as the core, with a certain size of the regional transport pattern. The use of advance- d computer, information, communication technology, establish and improve the transport and logistics information network, so as to lay a good foundation for the development of the 


\subsection{Help Enterprises to Solve the Problems in The Transport process}

Each Due to the impact of the economic system, most of our enterprises have large-scale storage facilities, and some even have a certain degree of transport capacity. This service self, everything does not seek the practice seems to be helpful to the enterprise, in fact, has become a burden in the process of enterprise development (Xinzhi Li, 2013). Large-scale construction not only increased production costs, but also to a certain extent hindered the development of transportation. At present, many business managers have realized that they should cooperate with third-party logistics enterprises, but they also worry that there will be such a problem: the storage facilities will be idle, engaged in transport work will be laid off. In this regard, we have to take certain measures to guide enterprises through third-party logistics companies in consultation with each other on the basis of mutual benefit to properly solve this problem. You can consider the two of the procurement, manufacturing, transportation, warehousing and sales links in series, forming a new logistics supply chain. We should continue to strengthen the technical exchanges and cooperation with the developed countries in the field of logistics, learn from and learn from the successful experiences of developed countries in developing logistics, keep abreast of the new trends of world logistics development, and combine with China's national conditions to perfect and form the characteristics of the Chinese nation as soon as possible Of the modern logistics system, better adapt to the needs of national economic development.

\section{ACKNOWLEDGEMENTS}

This work is supported by the Excellent Young Teacher Development Fund Project of Zhengzhou University and the Innovation and Development Fund of Zhengzhou University School of Management Engineering.

\section{REFERENCES}

[1] Xianglin Li, Jinpeng Zhang, 2015. Aviation express industry in China's development status and countermeasures [J]. Industry Economy, (2): 68-70.

[2] Jia Liu, 2016.Study on Current Situation and Development Tren- d of Railway Transportation Industry[J]. Enterprise Reform and Management, (5): 179-180.

[3] Huibin Gong, 2015. China's traffic economy development status quo and its countermeasures [J].Enterprise Reform and Management, (20): 203-204.

[4] Yilin An, 2016. China's logistics and transportation status and development path [J].Logistics Engineering and Management, (4): 10-11.

[5] Gang Cui, 2010. On the development of China's green logistics research and analysis [J].Heilongjiang Transportation Technology. (6): 123-124.

[6] Xinzhi Li, 2013. Third Third Party Logistics Enterprises and Manufacturing Enterprises Strategic Alliance Strategy 